\section{The '59ers'}

Shirley Zangwill reports on a 60th reunion of BDS graduates.

$\mathrm{I}$ n July 2019 the 1959 BDS graduates (well most of them who had not gone to that Great Dental Surgery in the sky) met in Edinburgh to celebrate their 60th year of graduation.

In many ways they were a remarkable year, producing the first woman in the United Kingdom to be given a personal chair, with a Professorship in Oral Medicine. Professor Dorothy Geddes also became the first female Dean of the Faculty of Dental Surgery of the Royal College of Surgeons of Edinburgh. She was given an OBE in 1995. Dorothy died of cancer at a relatively young age.

Ronald (Ronnie) Smart made his career in oral surgery in the British Army, rising to the rank of Brigadier. During his working life he held many important posts. He was Commanding Officer of the Military Wing, Musgrave Hospital in Belfast for which he was awarded the General Service Medal, with clasp, Northern Ireland. When he was in Hong Kong he was the first dental surgeon to be given the command of a Military Hospital. In 1994 he was appointed Honorary Dental Surgeon to the Queen and was awarded the Officer Order of St. John of Jerusalem in 1996.

John Gould was another with unique qualifications, having first qualified in medicine before joining the '59ers' to qualify in dental surgery. It seems impossible to find another consultant who qualified this way. Usually the dental degree comes first. Peter Brown was another successful consultant in oral surgery in Dundee and Ninewells Hospital.

Shirley Zangwill, née Punter [the author], became senior dental officer in the Community Service in Cambridge, working in hospital as well as community, treating HIV positive, haemophilia and Christmas disease patients and anyone who found it difficult to have treatment with a general practitioner because of a medical condition. Her work also included those who were too terrified to be treated in general practice.

Rob Thomson ran a superb and successful general dental practice in Windsor.

Zahi Khalaf still works in his prestigious practice in Beirut with his son, a graduate of Dundee Dental School. Zahi and his wife, Leila, organised various visits to Lebanon, Damascus, Egypt and Turkey not all at once of course. Winnie Hawkins, née Eason, was in general and orthodontic practice in the Northumberland area. She came, driven by her daughter Fiona, to join the reunion for lunch one day as she was not fit enough to attend for the whole three days.

Another remarkable graduate was Janetta Wood, who sat her exams and requalified in the United States, to teach oral medicine in Gainesville Dental School in Florida. Jan died at a young age, of cancer, as did Elspeth Walker, née Davidson, who was in general practice.

The reunion had reason to be very grateful to John Wylie, the cleverest person in the year, who was forced to cancel at the last minute. He required an operation, which had been delayed because of the illness, leading to the sudden death, of his wife, Moira. John very kindly and generously donated the refund of their prepaid dinner

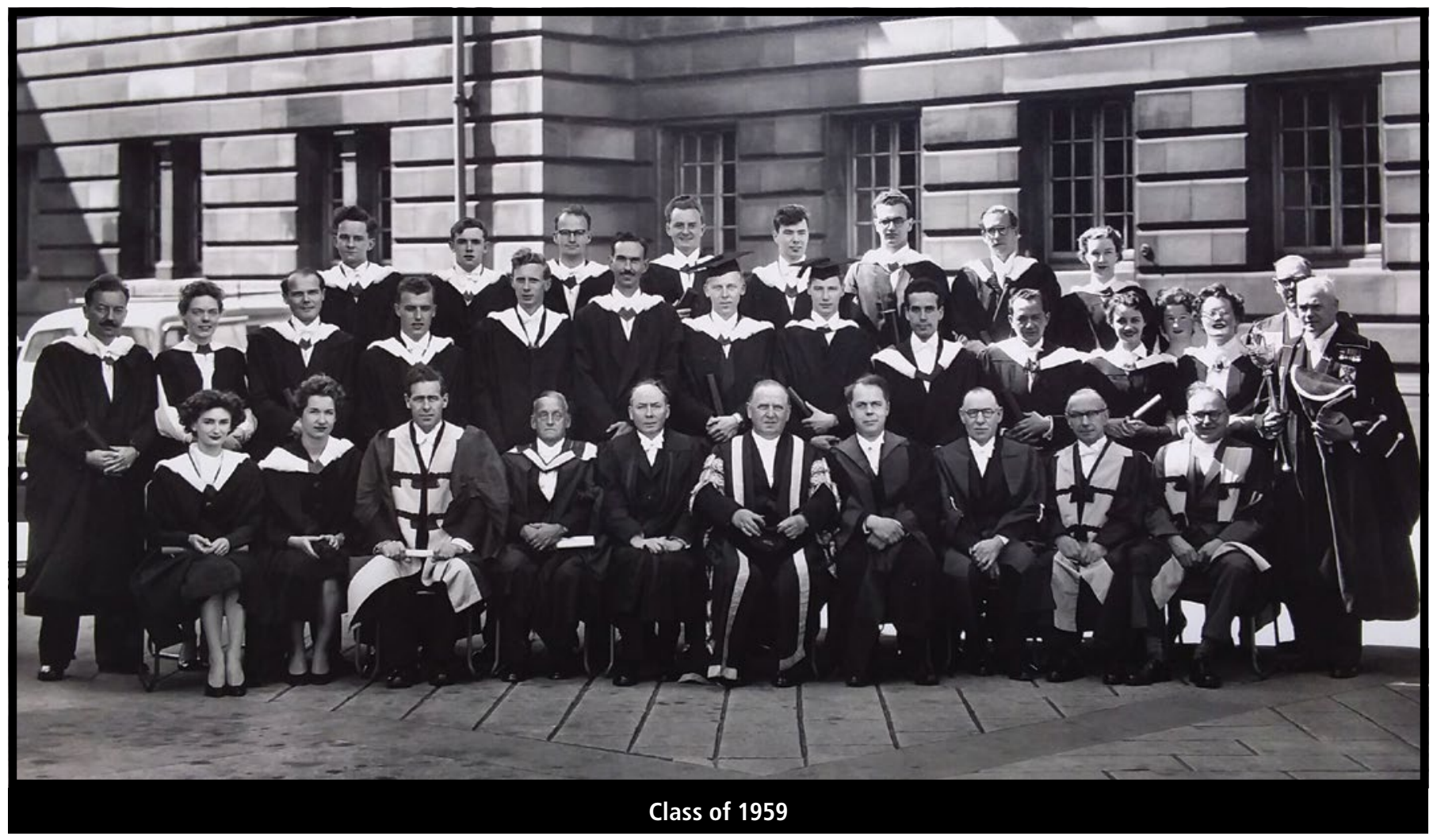




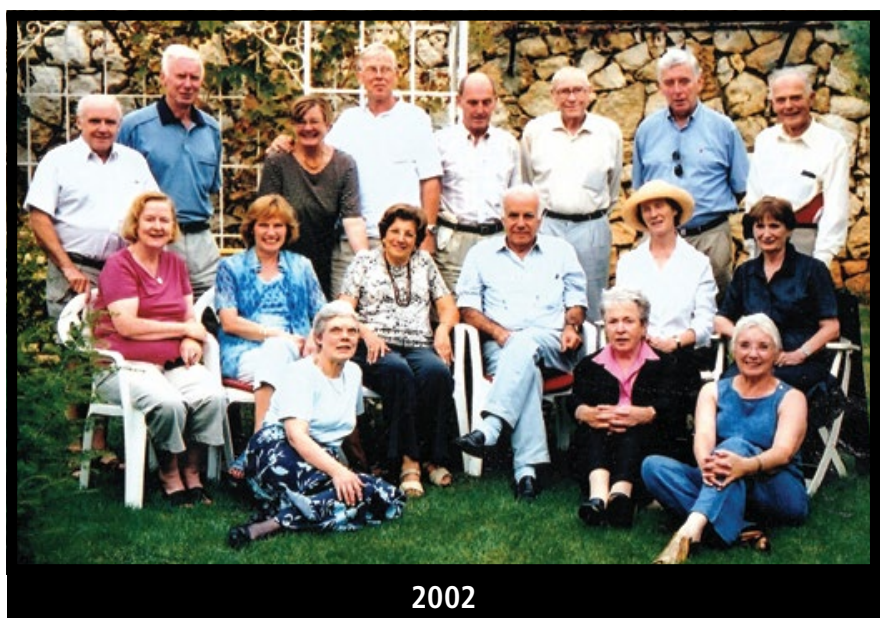

4 tickets to be spent, as befitted, during the reunion. It was used to great effect in supplying all the beverages, drunk with the dinners, on the first two nights. It was greatly appreciated and his name was well toasted.

Jim Ness, in Australia, keeps in constant touch with all who enjoy his 'funnies' but would not come the distance to join the reunion in Edinburgh. He was most interested, however, in the programme and photos taken of the final night's dinner.

We knew from previous correspondence, with his wife, Sidsel, that Odvar Kjoraas was too frail to travel now, but were sad we did not have any replies to our emails or letters. Frances Gould, née
Baillie, and John Gould organised the reunion through the College of Surgeons Hotel, obtaining a generous discount because of John's Surgical Fellowship. Shirley and Alison, Rob's wife, chose a wonderful menu for the Final Dinner. We are thankful to Frances, who has kept in touch with us all and organised the reunions in Edinburgh but gave the task of organising the one in Cambridge to Shirley. Frances, in turn, uses others as sounding boards for making arrangements, especially Shirley, without whom she couldn't function.

The photos show our graduate group in 1959; a picture of us in Lebanon in 2002; and a picture of us this year at the reunion. Can you spot the people after 60 years?

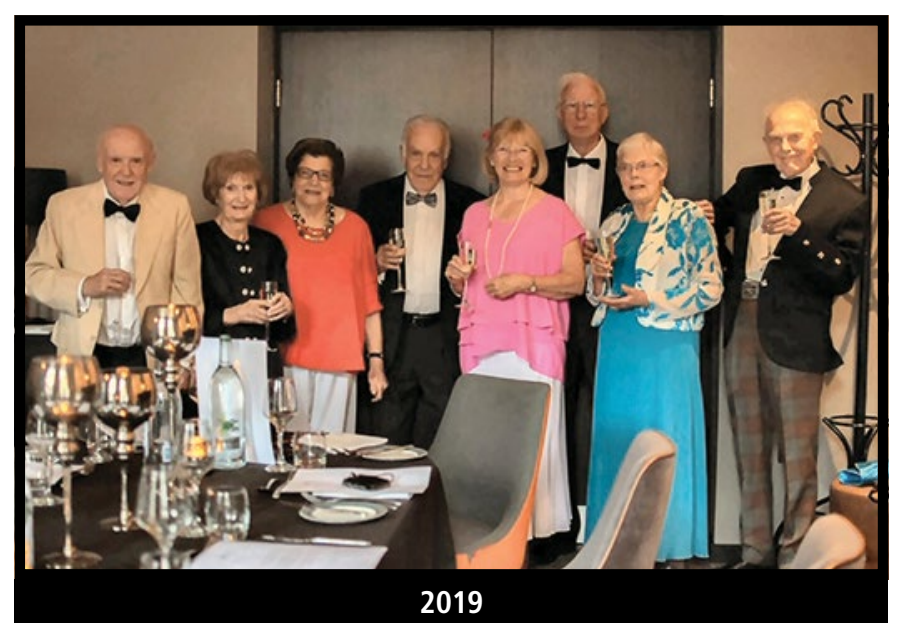

\section{Here has been an advertisement.}

\section{SPRINGERNATURE}

